\title{
Design of Intelligent Control System for Rice Whitening Machine
}

\author{
Jin Zhou \\ School of Electrical \& Electronic Engineering, Wuhan \\ Polytechnic University, Wuhan 430023, China \\ Hong Yue \\ Department of Electronic and Electrical Engineering, \\ University of Strathclyde, Glasgow G1 1XW, U.K \\ jin.scot@gmail.com; hong.yue@strath.ac.uk
}

\begin{abstract}
The product quality of rice whitening process has largely dependent on operation experiences, which is a key problem for this type of food processing systems that might lead to variability in the final product quality. An intelligent automatic control system has been proposed for rice whitening machines based on expert database system. The new control system replaces the traditional mechanical actuators with stepper motors, along with sensors and supervisory control and data acquisition (SCADA), achieving digital visualization of the rice whitening process. The operation experiences can be conveniently transferred into the expert database system in real time, allowing the control system to automatically select the relevant operation parameters. The developed scheme has been implemented in an industrial system at the trial stage. The preliminary results are positive in improving product quality and reducing labor intensity.
\end{abstract}

Keywords - rice whitening machine; automatic control; expert database system; intelligent control

\section{INTRODUCTION}

Rice is one of the most important cereals in the world. In recent years, with the emerging of large-scale rice processing production line, the most of them have realized the automation of production process. which has solved the rice processing line flow control and production process monitoring, improving production efficiency, and greatly reducing the labor intensity of workers. However, the operation of the rice whitening machine in the rice processing line is entirely dependent on skilled workers at present. The rice whitening machine, which determines the quality of processing, is the key milling equipment in the rice processing line. The control of whiteness (degree of milling) and percentage of broken kernels is done by skilled workers who adjust the pressure door in the outlet, according the color, translucent, temperature etc. of the milled rice. Due to the low cost of electricity at night, rice processing mills usually produce at night. It will make the workers who operated rice whitening machine very tired. All the facts together with the poor working environment (noisy and dusty) which may cause workers leave, will result in unstable production quality.

In order to reduce the labor intensity of workers and provide a stable quality of processing, an intelligent automatic control system based on machine vision and fuzzy logic had been developed [1,2,3]. However, due to its high cost and the wide variety of rice, this control

Supported by Technology Innovation Key Project of the Hubei

Providence Science and Technology (No. 2016ABA089)

\author{
Yonglin Zhang \\ School of Mechanical Engineering, Wuhan Polytechnic \\ University, Wuhan 430023, China \\ Chongye Xiao \\ Wuhan CFM Food Machinery Co., Ltd, Wuhan 430079, \\ China \\ ylz22@whpu.edu.cn; whzljx@vip.163.com
}

system in the short term is still difficult to solve the problems.

The intelligent automatic control system of rice whitening machine based on expert database system has been developed. The new control system of rice whitening machine replaces the traditional mechanical actuators with stepper motors, along with sensors and supervisory control and data acquisition(SCADA), achieving digital visualization of rice whitening. The experience of skilled workers can be transferred to the expert database system in real time, making the control system with the ability to automatically select the relevant parameters. With the increase of the rice processing time, the expert database system will be rich and optimized.

\section{MATERIALS AND METHODS}

\section{A. Rice Whitening Machine}

White rice is produced from brown rice by removing the bran layer and the germ in the rice whitening machine. The bran layer is removed from the kernel by applying friction to the grain surface either by rubbing the grains against an abrasive surface or against each other. The amount of bran removed is normally between $8-10 \%$ of the total paddy weight but this will vary according to the variety and degree of milling(DM) required [4].

Rice is used as wholegrains. Hence any breakage of the grain during milling is undesirable. There are two type of reasons can cause the breakage of rice, one is determined by the characters of the rice such as fissures, chalkiness, immaturity and rice kernels dimensions, rice kernel moisture content (MC), properties which are both cultivar and rice grain history dependent; the other reason is determined by the external reasons $[5,6]$, which could directly lead to the breakage of rice such as the temperature rise, the duration of rice milling and mechanical stress, etc. During the processing, rice kernels are subjected to mechanical stress which can lead to the heat generation. A main challenge of rice industry is to minimize the quantities of broken rice $[7,8,9,10]$.

The design is based on abrasive type whitening machine, in which the mechanical stress in the milling chamber is calculated as (1).

$$
\mathrm{P}=\frac{2}{3}\left(\frac{m v^{2}}{2}\right) \frac{N}{V}=\frac{1}{3}\left(m v^{2}\right) \frac{N}{V}
$$

Where $\mathrm{P}$ is the mechanical stress of the abrasive whitener (Newton per square meter), $\mathrm{m}$ is the mass of a grain of 
rice $(\mathrm{kg}), \mathrm{v}$ is the average velocity of rice (metre per second), $\mathrm{V}$ is the volume of the milling chamber (cubic meter), $\mathrm{N}$ is the number of rice grains. Equation (1) shows the effect of rice grain kinetic energy on the whitening stress. As the mass and velocity of each grain are not the same, where $\left(\left(m^{*}\right.\right.$ square of $\left.\left.v\right) / 2\right)$ is refers to the average kinetic energy of each grain. The rice fluid density in the milling chamber can be expressed as (2).

$$
\rho=\frac{N \cdot m}{V} \quad\left(k g / m^{2}\right)
$$

Hence, (2) can be simplified to (3).

$$
\mathrm{P}=\frac{1}{3} \rho v^{2} \quad\left(N / m^{2}\right)
$$

As can be seen from (2), the mechanical stress is related to the rice fluid density and the average velocity of the rice. In order to ensure the yield of rice, the speed of the milling roller usually remains the same. Therefore, the rice fluid density is the key factor affecting the mechanical stress, which can be achieved by adjusting the opening of the outlet. The diagram of rice grains fluid motion is shown in Fig. 1.

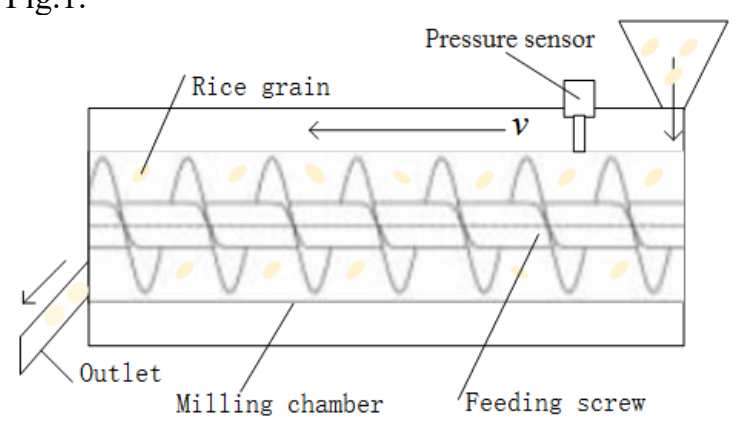

Figure 1. Rice grains fluid motion diagram

Also, gentle milling protects some defective grains from failing, while harsh milling leads to failure of more or all of them. To reduce the number of broken grains and the grain temperature during the whitening process, rice is normally passed through two to four whitening machines connected in series. Rice temperature should not exceed $43-44^{0} \mathrm{C}$ during any process [4]. A typical relationship between the percentage of broken rice and the temperature of rice at the outlet of the machine is illustrated in Fig. 2, from which it can be observed that the ratio of broken rice is increased with the increase of the temperature.

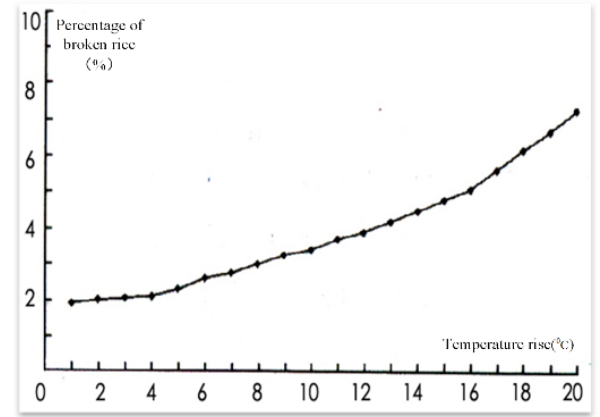

Figure 2. The relationship between percentage of broken rise and temperature rise

The feeding speed of the traditional rice whitening machine is adjusted by the manual sliding door in the bottom of feeding hopper, and the discharge speed and the degree of milling are adjusted by balance mounds on the outlets. In this design, the manual sliding door and the

Supported by Technology Innovation Key Project of the Hubei Providence Science and Technology (No. 2016ABA089) mechanical outlets including the balance mounds are replaced by electrical slide gates driven by stepper motors or permanent-magnet synchronous motor (PMSM) for low-cost design.

The block diagram of a rice whitening machine can be shown in Fig. 3, in which M1-M3 are PMSM which are used to control the degree of milling $[11,12,13]$. There are two sensors for each PMSM to identify the length of the PMSM that has rotated thus far. There is a sensor HL1 in the feeding hopper for flow control of the production line. Since the temperature and the broken rice rate is closely related, T1-T2 are used for detecting the temperature in the inlet and outlet of the machine. Also the current transformer, CT1, is used for detecting the load current of motor. A general melt pressure sensor (accuracy: $0.5 \%$ full scale out combined error) shown in Fig. 1 is mounted on the wall of the milling chamber, which is mercury free.

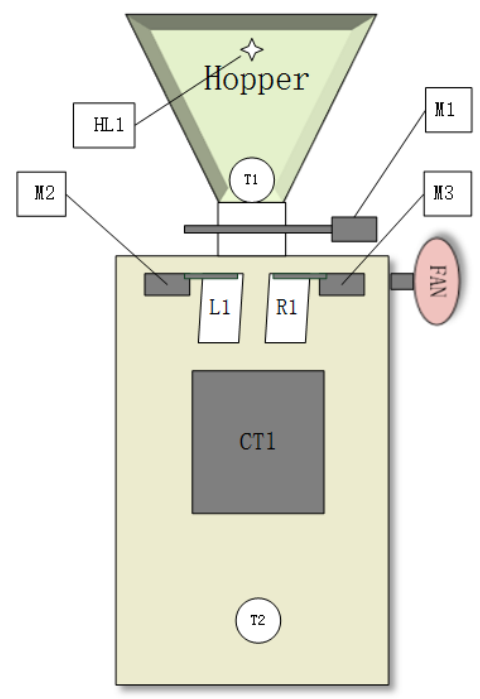

Figure 3. Rice whitening machine

\section{B. Structure of Control system}

Block diagram of the developed automatic control system network is shown in Fig. 4 in which all the parts are connected via Simens PROFINET network using the Ethernet standard for automation.

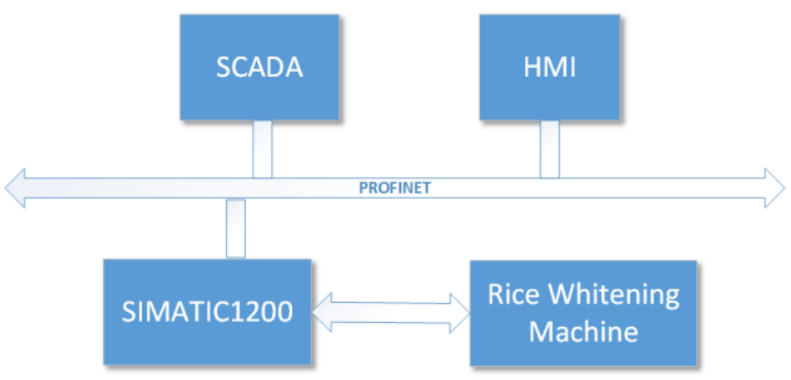

Figure 4. Block diagram of control system network

All field-related data including HL1, T1-T2, CT1, the position signals of three stepper motor, pressure sensor signals, other motors status signals are collected by PLC Simatic1200. The stepper motors are driven by 
SINAMICS V90 ROFINET which are equipped with an integrated PROFINET interface for linking the drive to an automation system via PROFIdrive profile. Also the control algorithm for temperature and mechanical stress and some logic control are implemented in Simtaic1200. As mentioned above, the temperature which is generated by mechanical stress is main reason of broken rice, so the control system has set a maximum temperature The control algorithm is used to achieve the best parameters which is opening degree of outlets for a certainty processing circumstance in this design.

Human Machine Interface(HMI) is used to set and monitor operating parameters in the control system, such as rice temperature in different places, degree of milling, the feeding valve, motor current(CT1), the sensor in the feeding hopper, etc. The control system can operate in automatic or manual mode by HMI setting. Also it is used to adjust the opening degree of the outlets which are driven by three PMSMs by the skilled workers when the machine is in a manual operation mode. The HMI includes the processing data and system setting which can be access in other pages. The main interface is shown in Fig. 6 .

Host computer(SCADA) is used to complete the data storage, sorting, the establishment of the database, which can be integrated into the SCADA system of rice automation production line usually. The design has chosen KingView as a development platform of SCADA also in which the real-time data and historical data can display in curve mode besides in data-output mode and report mode. The design used Curve to display the change of temperature in which $\mathrm{X}$ axis stands for time and $\mathrm{Y}$ axis stands for rise of temperature tag value. Meanwhile, the historical trend Curve was used to show the value of history parameters, etc.

\section{Aanlysis of the control scheme}

The whole intelligent control scheme and the structure are shown as Fig. 5 and Fig.7. The first step of the control system is to collect the experience of skilled workers and transfer the data to ACCESS database which will be reorganized by expert system.

The second step is to adjust the operating parameter variables which are the opening degree of the outlets to achieve maximum yield, satisfying the demand of the degree of milling under a certain operating circumstance, meanwhile the broken rice and power consumption are minimized by Fuzzy logic control strategy.

The operation of skilled workers is to control the flow by adjusting the pressure of the milling chamber which is actually a repeated operation for every time. In view of the fact that people are repeating the operation process, the third step is to use the iterative learning control technique to correct the control parameters using the errors measured at the previous or several operations, making the repetition task better at the next time.

As mentioned above, in the modern processing of rice mill, a rice whitening machine set are used to mill the brown rice gradually, which are featured with overall and decentralized control. Each one in the set needs to coordinate with each other, therefore, in the last step the hierarchical control is used for the machine set. The control system is realized by three parts which is shown as Fig. 7 where F2 is the basic control system, F3 is an upgraded control system which have more sensors, and F4 is the intelligent control system which is used for rice whitening machine set.

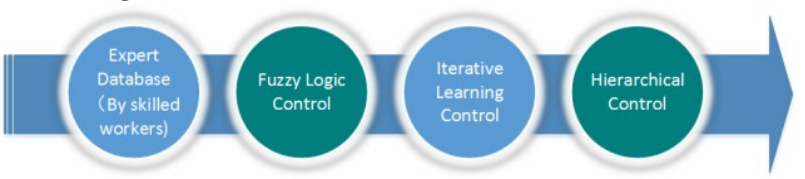

Figure 5. The intelligent control scheme

\section{Expert database system design}

According to the rice processing requirements, all parameters are divided into six categories shown in Table I where the degree of machine wear refers to the use of

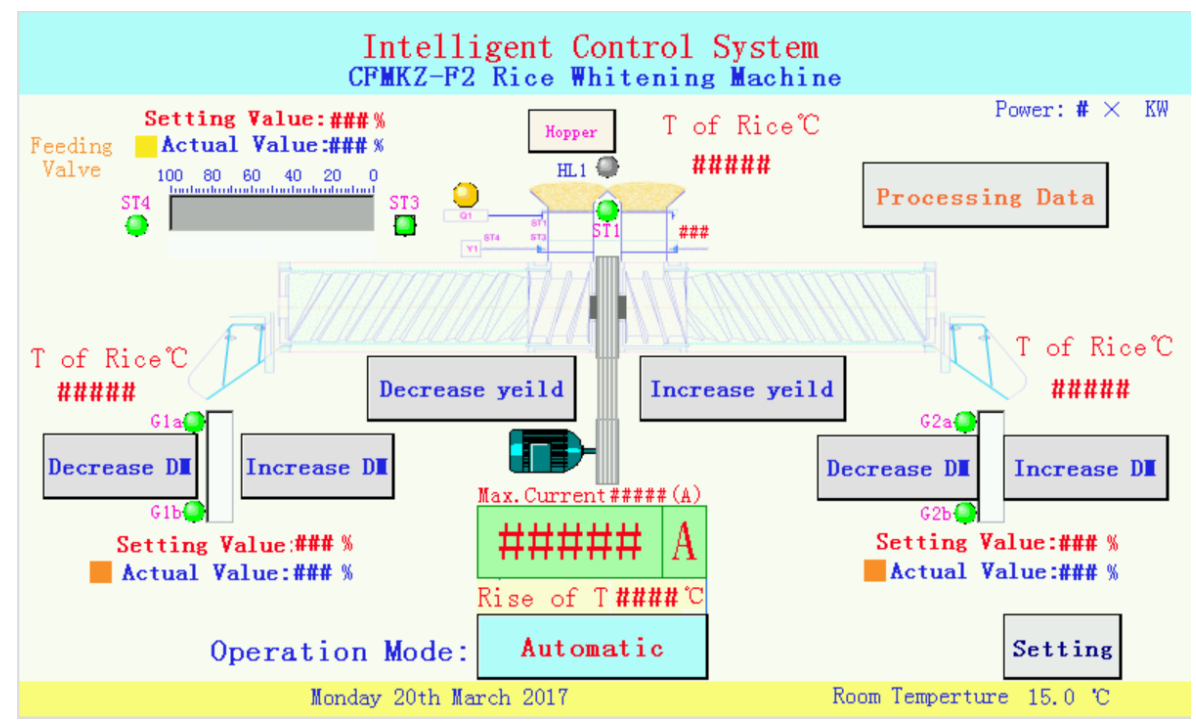

Figure 6. Main interface in Touch Screen 


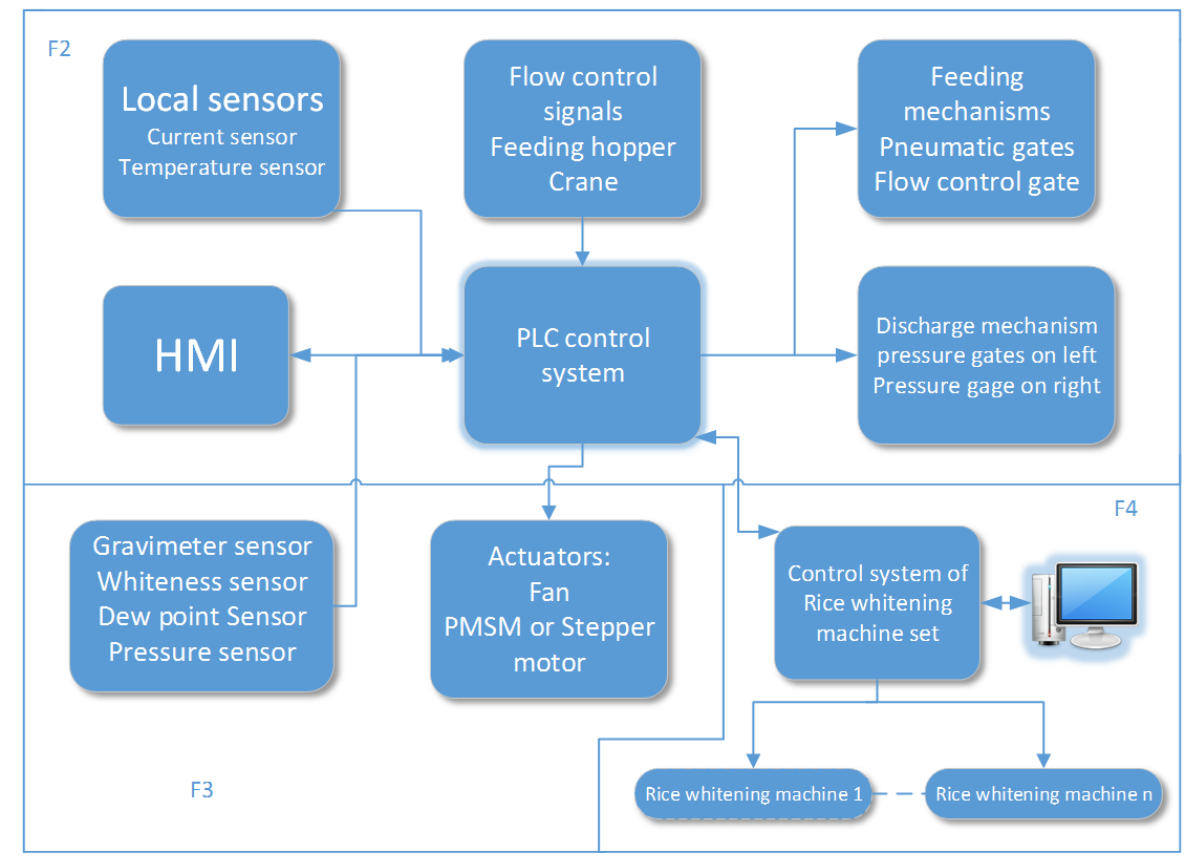

Figure 7. The intelligent control structure

feed roller. There are six tables established by ACCESS as basic database. Additionally, there is a result table which is used to save total result for each processing result for use as query. The worker on duty on every time after the end of each rice variety processing add a record including the most important parameters, such as type of rice whitening machine, rice varieties, degree of milling, machine loss, temperature rise, broken rate, power consumption, the opening degree of feeding gate opening, opening degree of outlets.

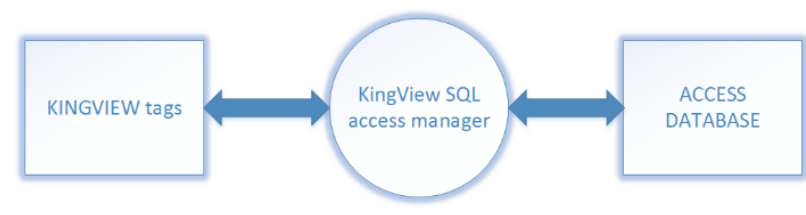

Figure 8. Data variables relationship

Data variable relationship graph is shown in Fig. 8. Corresponding with the variables in the ACCESS database.

First of all, the KingView tags need to be built. The common tag can be used for most of field signals. However, as the wide variety of rice varieties, control parameters, rice mill types, therefore, structure tags of KingView are used for rice varieties and parameters of rice whitening machine. Otherwise the system has to define loads of tags. Structure tag is to use defined template to define tag. The definition of a structure tag is shown in Fig. 8, which are LongGrainRice. The template contains several members which are the different parameters of one type of rice. As the defined tag type is the template data type, all the members of the template become the basic tag of KingView. Also other similar such as control parameters, rice mill types etc. are defined like Fig. 9 as well.

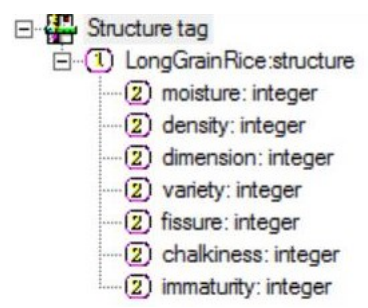

Figure 9. The definition of a Structure tag: LongGrainRice

Secondly, KingView SQL access functions are for transferring data between KingView and other ODBC database. It contains KingView SQL access manager, configuring connection with ACCESS database. KingView can exchange data with ODBC access interface. So it is needed to add database in system ODBC data source first, then make all operations by KingView SQL access manager and SQL functions.

There are two ways to access and operate the data in the database file. The one is to use KingView SQL functions which can be called in any scripts. It can create tables, insert or delete records, edit table, clear or delete tables and search records by them. The other solution that has less flexibility but more easy to use is to use ADO control in KingView called KVADODBGrid control, by which various functions of control properties, methods and events can be invoked to operate the control.

Lastly, a database file is created by Microsoft ACCESS, which includes six tables which are defined in Table. I. Then the ACCESS database file is registered as an ODBC data source by ODBC Administrator in Windows Control Panel. 
TABLE I. PARAMETERS OF PROCESSING DATA

\begin{tabular}{|c|c|c|c|c|c|c|c|}
\hline Table & Name & Field 1 & Field 2 & Field 3 & Field 4 & Field 5 & Field 6 \\
\hline Table 1 & $\begin{array}{c}\text { Rice } \\
\text { varieties }\end{array}$ & Name & $\begin{array}{c}\text { Rice } \\
\text { Moisture } \\
\text { Content }\end{array}$ & $\begin{array}{l}\text { Head milled } \\
\text { rice rate }\end{array}$ & Aspect ratio & $\cdots$ & \\
\hline Table 2 & DOM & $\begin{array}{l}\text { Degree of } \\
\text { Milling }\end{array}$ & I & II & III & IV & $\ldots$ \\
\hline Table 3 & Machine loss & $\begin{array}{c}\text { Machine } \\
\text { loss }\end{array}$ & Loss 1 & Loss 2 & Loss 3 & $\ldots$ & \\
\hline Table 4 & $\begin{array}{c}\text { Indicator } \\
\text { parameters }\end{array}$ & $\begin{array}{l}\text { Indicator } \\
\text { parameters }\end{array}$ & $\begin{array}{c}\text { Effective } \\
\text { milling time }\end{array}$ & $\begin{array}{c}\text { Room } \\
\text { temperature }\end{array}$ & $\begin{array}{l}\text { Temperature } \\
\text { rise }\end{array}$ & $\begin{array}{l}\text { Broken } \\
\text { rate }\end{array}$ & $\begin{array}{c}\text { Power } \\
\text { consumption }\end{array}$ \\
\hline Table 5 & $\begin{array}{c}\text { Control } \\
\text { paramerters }\end{array}$ & $\begin{array}{l}\text { Status of } \\
\text { devices }\end{array}$ & $\begin{array}{l}\text { Feeding } \\
\text { gate } \\
\text { opening } \\
\text { degree }\end{array}$ & $\begin{array}{l}\text { Discharge } \\
\text { gate opening } \\
\text { degree.(left) }\end{array}$ & $\begin{array}{c}\text { Discharge } \\
\text { gate opening } \\
\text { degree.(right) }\end{array}$ & $\cdots$ & \\
\hline Table 6 & $\begin{array}{c}\text { Type of rice } \\
\text { whitening } \\
\text { machine }\end{array}$ & Type & Power & $\begin{array}{c}\text { Number of } \\
\text { motors }\end{array}$ & Rated current & $\begin{array}{l}\text { Motor } \\
\text { effiecent }\end{array}$ & $\cdots$ \\
\hline
\end{tabular}

In this design, the most suited record will be selected from the result table, according to the index parameters of temperature rise, broken rice rate or power consumption of the order. The flow chart of Sorting and querying in the result table is shown in Fig. 10.

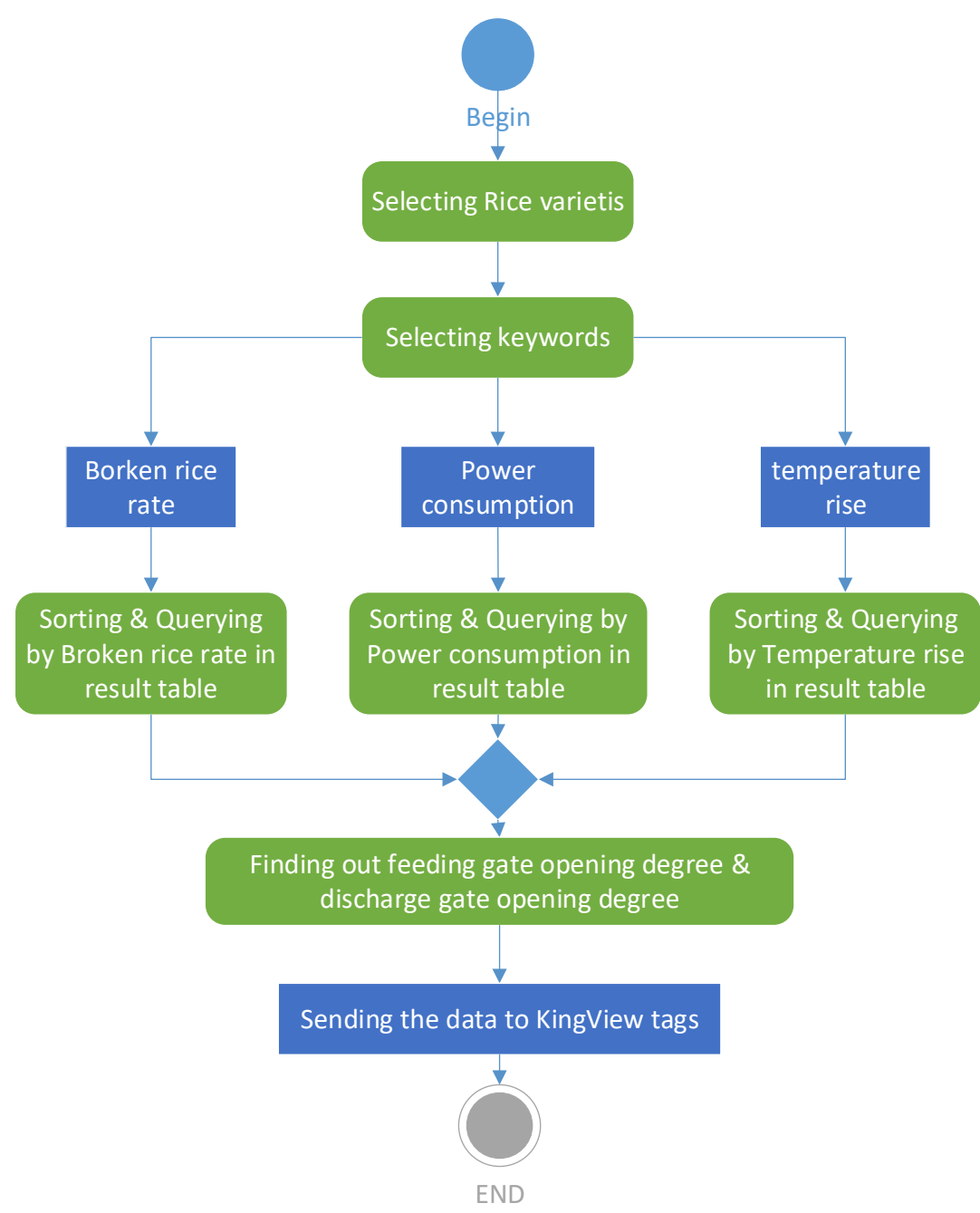

Figure 10. Flow chart of sorting \& querying in result table 


\section{CONCLUSION}

Using a simple low-cost strategy, the Intelligent Control System for Rice Whitening Machine based on expert database have solved the key problems in the rice millers that the product quality has seriously relied on skilled workers, high labor intensity.

The rice whitening machine using this new intelligent control system has been officially put into a production line in Hubei, China, and has been used in one rice miller for 6 months. The key technique has been submitted for patenting. In the next stage, the system will be further developed to enhance the modelling of machines and also the expert database system so that the overall intelligence level can be improved.

\section{REFERENCES}

[1] H. Zareiforoush, S. Minaei, M. Reza Alizadeh, A. Banakar, B. H Samani, "Design, development and performance evaluation of an automatic control system for rice whitening machine based on computer vision and fuzzy logic", Computers and Electronics in Agriculture, no. 124, pp. 14-22,124, 2016.

[2] B. K. Yadav, V. K. Jindal, "Monitoring milling quality of rice by image Analysis", Computers and Electronics in Agriculture, no. 33 , pp. 19-33, 2001.

[3] S. Kawamura, M. Natsuga, K. Takekura, K. Itoh, "Development of an automatic rice-quality inspection system", Computers and Electronics in Agriculture no.40,pp. 115-126, 2003.
[4] Rice Milling, International Rice Research Institute (IRRI), <http://www.knowledgebank.irri.org>, accessed 10 May, 2017

[5] P. Zhou, H. Liu, K. S. Tan, C. Chen, "Application and Research of Fuzzy Control Simulation in Twin Screw Extruder", International Workshop on Information and Electronics Engineering, Engineering, vol. 29 pp. 542-546, 2012

[6] J. Buggenhout, K. Brijs, I. Celus, J. A. Delcour, "The breakage susceptibility of raw and parboiled rice: a review", Journal of Food Engineering, vol. 117, no.3, 304-315, 2013

[7] R. C. Bautista, T. J. Siebenmorgen, P. A. Counce, "Rice kernel dimensional variability trends", Applied Engineering in Agriculture vol. 23, no. 2, pp. 207-217, 2007

[8] K. R. Bhattacharya, "Breakage of rice during milling, and effect of parboiling”, Cereal Chemistry, vol. 46, pp. 478-485, 1969

[9] Q. Zhang, W. Yang, Z. Sun, "Mechanical properties of sound and fissured rice kernels and their implications for rice breakage", Journal of Food Engineering, vol. 68, pp. 65-72, 2005

[10] K. R. Bhattacharya, "3-Milling quality of rice, Rice quality" A guide to rice properties and analysis, Woodhead Publishing Limited, 2013

[11] Y. L. Zhang, Q. W. Yi, W. P. Wang, L. H. Zhou, "Design of new type of vertical rice whitening machine set", Transactions of the Chinese Society for Agricultural Machinery, vol. 37, No. 10, 2006.

[12] Y. L. Zhang, Z. G. Hu, W. P. Wang, L. H. Zhou, "Research and development of new type rice whitener with low operation pressure and high eff iciency, Transactions of the CSAE", vol. 23, no. 4, 2007.

[13] Y. L. Zhang, Q. W. Yi, W. P. Wang, L. H. Zhou, "Innovative design of rice polisher with intelligent dampening and pressure control system", Transactions of the CSAE, vol. 22, no. 7, 2006. 